\title{
Revenue of Power Utilities and the Impact of Externalities on Realization
}

\author{
Nirmalendunath Ghosh \\ Ex-superintending Engineer (electrical) SEB, Kolkata
}

\begin{abstract}
Electricity utilities faces challenge to meet growing demand of electricity, but maintaining the quality of service need better financial resources which is possible only if appropriate revenue return is achieved by selling the electricity. This study is based on the concept that externalities has positive or negative role on the system functioning which in turn affect revenue growth, there is necessity to define the relationship between externalities and revenue return to develop a strategy to counter the impact of externalities and internal element on revenue optimization. The study aim to find out which externalities have impact on revenue growth, how that affect revenue growth and what are the issues associated to counter negative effect of externalities on the system. The methodology is to analyze data from electricity utilities followed by statistical analysis to derive a relationship between independent and dependent variables in system operation.
\end{abstract}

Keywords: revenue, externalities, electricity utility, economy

\section{Introduction}

Revenue management in the system is an important issue pertaining to sustainable growth of the organization. But the system is open to environment that is interacting with other systems for its survival of its existence in industry. Therefore, there are some external elements in the environment which are influencing system operation in the different area of activities of the system. Present study is directed to find out the scope of revenue growth in the electricity utilities. Revenue is the final reality of the system performance in the supply chain, so the quantitive value is dependent on the process that begins with resource utilization, then Transformation of resources into product, decision on fixation of product cost on the basis of the cost of resource as well as cost of operation and mode of distribution of the product with control on efficiency of collection of revenue for the complete product output. However there would be some losses inevitably according to the law of thermodynamics besides, the losses due to technical and commercial constraints. Moreover, Revenue management involves other dimension of the electricity utilities which are system demand, Human resource quality and resource mobilization that are internal controllable variables but subject to external element influences. In India, economy of the states is of diverse type that involves more industrial intensive or agricultural intensive or services intensive characteristics. Again the climate across the country is not uniformly favorable to sustain human livelihood. The demand of electricity is varying with erratic climatic condition, especially agriculture is mostly depended on the climatic condition and services consumption is changing with season change. Also in some region climatic effect is more vulnerable to sustain normal routine life, the example is draught situation in northern and central india.Another issue of the impact on revenue is diversity in socio economic condition of the Indian states. Though the electrification has been completed fully in many states there is deprivation in access to the electricity supply, because of economic reasons, that is driving unaccountable energy consumption. There are also policy issues in governance of the utilities on connection and disconnection of electricity supply or tariff structure. Another important attribute to revenue growth is human resource management in revenue realization activities that needs more advanced technology oriented infrastructures. Thus revenue growth in system may be attributed to managing controllable dimension and facing the challenge of uncontrollable dimension which are economy of the states, climate of the region and socio economic status of the states. This study on the revenue growth in electricity utilities is focused on the justification of hypothesis that impact of the external element on the electricity utilities system is a driving factor of revenue growth which is also interrelated to controllable internal dimensions in the system. The objective of this study is to determine how the external elements are affecting revenue growth and developing a strategy to overcome the constraints. The study analyzed the performance of some sample state utilities in revenue management to ascertain actual scenario of the above relationship between the different dimension of system demand, resource value and the performance of human resources and their skill development. After unbundling of electricity utilities, the generation, transmission sector depends financially on revenue realization in distribution sector. Generation sector sell the electricity to power trading corporation, transmission authority transport electricity at the cost recovering from distribution utilities. So, ultimate return of revenue is dependent on the distribution utilities. Therefore, the generation and transmission sectors are dependent on the distribution utilities to sustain in electricity supply industry. The major criterion of sustainable revenue growth is reducing 
gap between average cost of electricity supply and average revenue return .The revenue return is depended on price of electricity for consumption. This is controlled by regulatory commission according to the merits of the system requirement in parity with resource utilization and consumer density in different categories in different states. This study has analyzed the revenue growth and impact of externalities in different scenario comprising relation with economy, climate, socio-economic and policy issues in governance that has been organized in different sections. The data for this analysis has been collected from different institutions web portal both in quantify and qualitively, then statistical analysis performed to justify the hypothesis in next part, followed by the result and discussion on the analysis in subsequent paragraphs.

\subsection{Revenue growth and diversity in economy of states}

In India, the regional economic diversity is influencing the electricity sale of the utilities. The western region is dominated by industrial categories of consumer, whereas, the northern region is comprised of mixed type of consumer categories. Economy based on agricultural work is driving the trend of electricity consumption in the large area of UP, Haryana,Punjab and Rajasthan. There is difference in tariff structure of agricultural consumers in different states that inevitably affect revenue growth of the electricity utilities. In case of western region, industrial based economy is driving electricity utilities' revenue realization and the tariff is quite high compared to agricultural and services consumers. Therefore, the contribution of electricity sector to State GDP growth is comparatively higher than other region of the country. The mixed type of economy in southern and eastern region is determining the requirement of electricity and realization of corresponding revenue. Actually, definite correlation exists between state GDP and the growth of revenue subject to other constraints that has been analyzed based on the report [1].The following TABLE1 indicate pattern of correlation between growth of revenue realization by the electricity utilities and contribution of electricity sector to state GDP growth In order to validate the concept that economy of the state has impact on revenue realization by the electricity utilities, the interrelation between Growth of contribution of electricity sector to state GDP growth and the

Table 1 correlation between economic growth (SGDP) and Revenue growth in states

\begin{tabular}{|l|l|l|l|}
\hline \multirow{2}{*}{ Year } & \multicolumn{2}{|l|}{ Standard deviation } & Correlation coefficient \\
& GDP growth & Revenue growth & R $^{\wedge}$ \\
\hline $2009-10$ & 37.85 & 82.54 & 0.591 \\
\hline $2010-11$ & 390.66 & 7.76 & 0.574 \\
\hline $2014-15$ & 1060 & 14.25 & 0.845 \\
\hline
\end{tabular}

Source: Data .gov. /in and PFC performance report of state utilities

revenue need be established, therefore, a statistical exercise has been done in order to find out correlation co efficient $\left(\mathrm{R}^{\wedge} 2\right)$...Accordingly, the relevant data in respect of GDP and revenue realization has been collected from relevant web portal[1][2].Since there is limited scope for detail analysis in this exercise, it has been focused on the profit earning or loss incurring states on revenue accrual basis during the year 2009 -10,2010-11 and 2014-15[1].It has been observed that correlation co-efficient is around 0.6 during 2009-10 and 2010-11 while co-relation co-efficient in 2014-15,it is 0.845 .Therefore,statistically it is observed that contribution of electricity growth to GDP growth and aggregate revenue of the electricity utilities is highly correlated to each other. So, it has justified the proposition that economy of the states externally affect revenue growth in electricity utilities.

\section{Micro Level Analysis On The Impact Of Economy}

Now, it is necessary to know which of the economy related to agricultural, industrial and services has impact on the revenue growth of the states. That the revenue realization corresponding to sale of the electricity is largely dominated by the pattern of state economy -agricultural,induatrial or services consumers has been assessed by looking into the statistics about intensity of agricultural, industrial and services contribution to GDP , per capita income and population that will indicate which of the dimensions are influencing the revenue realization corresponding to Demand of the consumer base which are different because of the difference in status of the state's economy. The statistics of the states profile on this issue corresponds to profit making or loss incurring states based on aggregate revenue accrual report of the corresponding states.[1] (TABLE 2) 
Table 2 Economy of the states and revenue realization of the selected states Report, Planning commission, directorate of economics and statistics, Karnatak

\begin{tabular}{|c|c|c|c|c|c|c|c|}
\hline \multirow[t]{2}{*}{ States } & \multirow{2}{*}{$\begin{array}{l}\text { Profit or } / \text { loss } \\
\text { on aggregate } \\
\text { revenue } \\
\text { realization }\end{array}$} & \multicolumn{4}{|c|}{ Type of economy 2014-15 } & \multirow[b]{2}{*}{$\begin{array}{l}\text { Per capita } \\
\text { income@ } \\
\text { current price }\end{array}$} & \multirow[b]{2}{*}{$\begin{array}{l}\text { Household } \\
\text { Nos. }\end{array}$} \\
\hline & & $\begin{array}{l}\text { Agricultural } \\
\text { Intensive(shar } \\
\text { e of GDP) } \\
(\%)\end{array}$ & $\begin{array}{l}\text { Industrial } \\
\text { Intensive (\%) }\end{array}$ & Services (\%) & $\begin{array}{l}\text { GSDP } \\
l^{*} \text { NSDP } \\
\text { growth (\%) }\end{array}$ & & \\
\hline Maharashtra & Profit & $7.88(12-13)$ & $28.41(12-13)$ & $63.71(12-13)$ & 155 & 117091 & 12115580 \\
\hline Delhi & Profit & 1.75 & 1.76 & 10.3 & 9.33 & & 3340538 \\
\hline Gujarat & Profit & -6.96 & 7.12 & 12.70 & 7.96 & & 12181778 \\
\hline WB & Profit & $17.11(12-13)$ & $18.33(12-13)$ & $64.56(12-13)$ & $6.72(12-13)$ & 36527 & 20067299 \\
\hline Karnataka & Profit & 31.54 & 18.09 & 17.35 & 7 & 89545 & 13179911 \\
\hline UP & Loss & $4.73(12-13)$ & $2.03(12-13)$ & $8.09(12-13)$ & $5.92(12-13)$ & & 32924366 \\
\hline Rajasthan & Loss & 19.43 & 30.58 & 49.99 & 5.75 & 33186 & \\
\hline Tamilnadu & Loss & $\begin{array}{l}7.69 \\
(2010-11)\end{array}$ & $\begin{array}{l}15.32 \quad(2010- \\
11)\end{array}$ & $\begin{array}{l}12.80 \\
(2010-11)\end{array}$ & $\begin{array}{l}13.12(2010- \\
11)\end{array}$ & 112664 & 7.21 \\
\hline MP & Loss & $18.63(12-13)$ & $18.41(12-13)$ & $8.10(12-13)$ & 21.9 & 54030 & 7.26 \\
\hline J\&K & Loss & $20(12-13)$ & $24.43(12-13)$ & $55.57(12-13)$ & 0.4 & 30612 & 1.25 \\
\hline
\end{tabular}

Source: economic survey of Maharashtra, Karnataka, PFC state performance, DCH

The state wise analysis reveals that one of the profit making state Maharashtra has developed a consumer base which has per capita income much higher than the other states, in addition to industrial and service sector contribution to SGDP[3].On the other side, J\&K has registered loss due to poor SGDP and poor per capita income. Delhi with services dominated consumers has registered profit because of growth of SGDP and high per capita income of urban consumer base.Gujrat represent a well economic consumer base that is advantageous for revenue growth, similarly Karnataka is economically well because of satisfactory contribution from agricultural and industrial consumer base and per capita income is high enough to boost revenue realization .Though Tamilnadu has a consumer base of high income level, but the contribution of agricultural sector is marginal because of tariff policy, therefore impact of externalities attribute to losses in spite of high level of SGDP.This analysis thus clearly highlight about the influence of state economy on the growth of utilities' revenue realization.

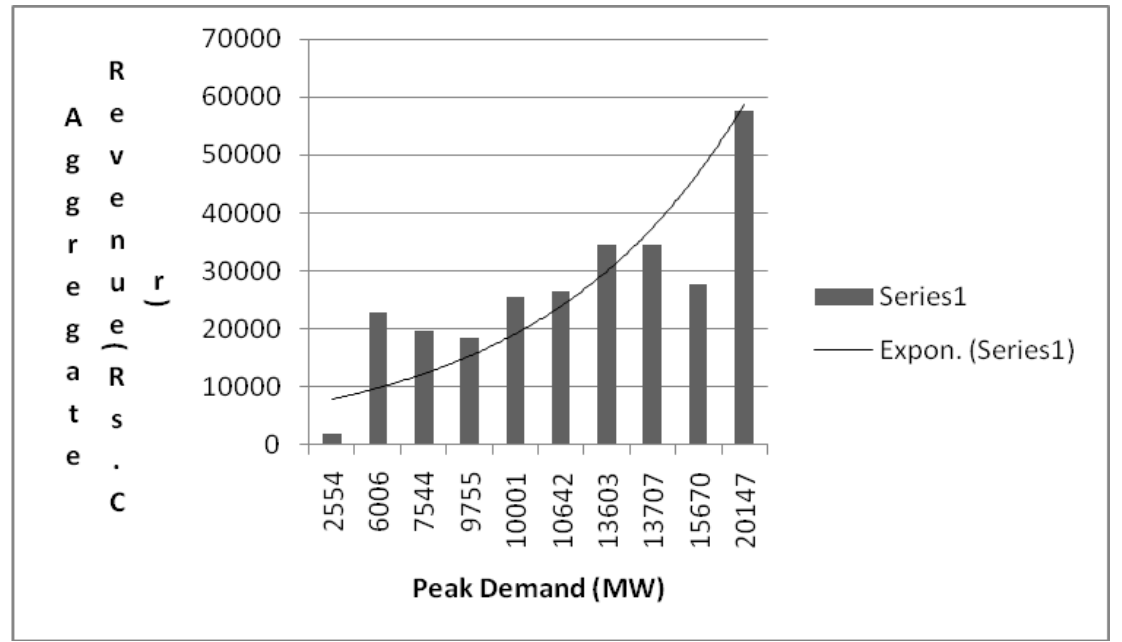

Source: prepared own, data PFC \&CEA

Figure 1: Impact of external factors in driving peak demand and its effect on aggregate revenue

Now the analysis will focus on the energy demand of the system with revenue realization in the states that were ranked in top of profit registered states and loss registered states in the bottom of the rank according to report[1].Though the tariff is different in the different states, the increase or decrease in demand implies the trend of consumption in different economy intensive states.Considereing the period 2014-15, while average tariff in Maharashtra is 617 paisa per kwh,MP charge their consumers @ average tariff of 629.34 paisa per kwh,Gujrat's average tariff rate is $405 \mathrm{p} / \mathrm{kwh}$,tariff of Delhi electricity(BYPL,BRP\&NDPL) is $587-651.53$ $\mathrm{p} / \mathrm{kwh}$,delhi (NDMC) is $467.5 \mathrm{p} / \mathrm{kHz}$.On the other side $\mathrm{J} \& \mathrm{~K}$ is a loss registered utilities where tariff is 213 $\mathrm{p} / \mathrm{kHz}$ [data.gov.in]. Thus tariff structure is a key issue in revenue growth. The trend of the curve (fig 1) implies revenue realization is in consistence with the peak demand though the pricing is different in the different states. Mathematically the relation between economy of the states as signified by SGDP and the revenue growth can be expressed as 


$$
R p=f\left(e^{\wedge} X\right)+f u(t)(p, p t)
$$

Where $r(p)$ is revenue growth, $X$ is contribution of the economy sector to GDP, $\mathrm{U}(\mathrm{t})$ is index of ratio average demand /maximum demand.

\section{Revenue Realization And Climate Of The Region}

Besides the influence of the state economy on the revenue realization, the concept of the influence of climate and the corresponding growth of demand due to socio-economic development has been analyzed. It is known that the south-West monsoon has considerable impact on the growth of economy, especially the agricultural sector is sensitive to monsoon activities, therefore the electricity requirement which is driving input to agricultural sector will be changed according to the changing pattern of monsoon onset in India Moreover, economy in India greatly depend upon agricultural production. Agricultural field are rain fed, so the agricultural work is mostly depended on good monsoon. Climate is not uniform across the states in India. Eastern, Northern Central, Southern and Western region is more sensitive to either extreme rainfall or draught. Seasonal change in temperature and humidity combined with natural hazards affect economy of the states, however, revenue growth in the different states need be analyzed keeping in view the change in climate across the country. This analysis has been done by collecting rain fall data [4] and State gross domestic product (SGDP) [3].SGDP data is taken as proxy to economy growth corresponding to contribution of electricity to GDP and rainfall data as proxy to climate. The graph has been presented in Fig 2.

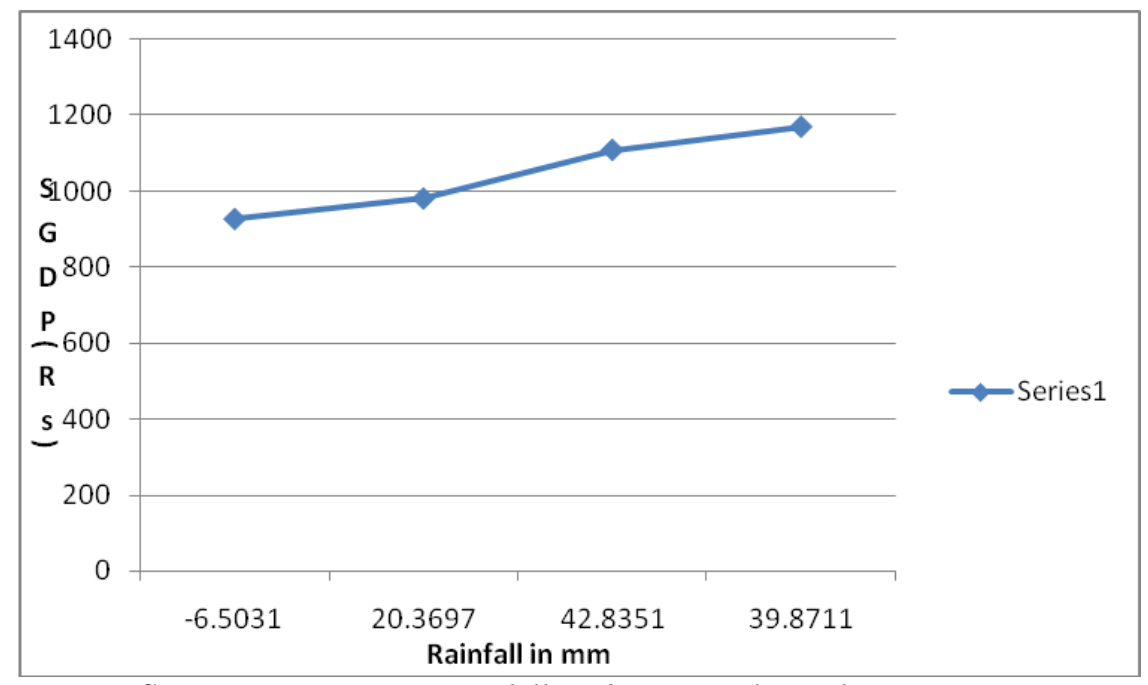

Source; District wise rainfall, Indian Metrological Department

Figure 2 Rainfall in the states and corresponding trend of electricity contribution to SGDP in UP 2011-12 to 2014-15

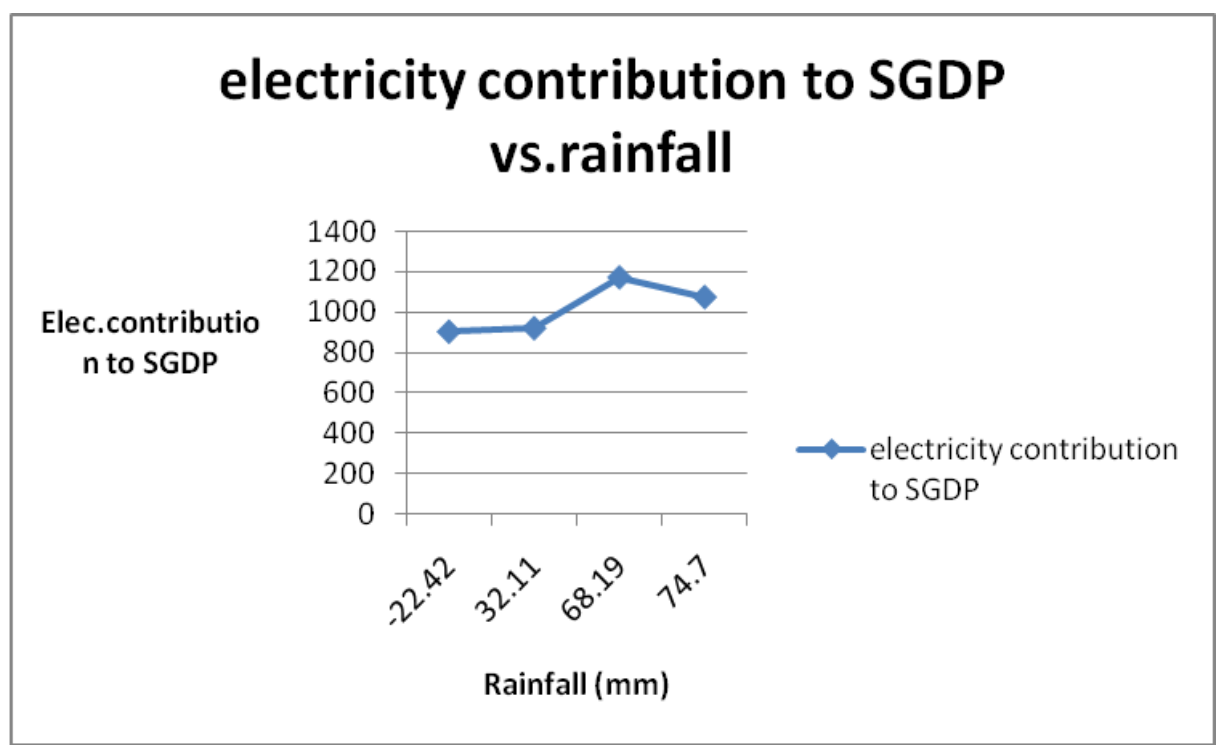

Fig 3 contribution of electricity to SGDP in MP during 2011-12 to 2014-15 
The graph in fig 2 \& fig 3 visualizes a relation between contribution of electricity industry to state GDP and rainfall in the state of UP and MP.The pattern is linear with increasing trend, these graph represent how revenue growth is related to climate of the region. Here rainfall $(\mathrm{mm})$ pattern is taken as proxy to climate over the region, logically it is justified, because agricultural growth is key economy factor in India where major agricultural work is rain fed. This interrelation between the variables implies that whenever the monsoon is fully active in the states, the economy growth boost up electricity utilities revenue growth pattern. But there is limitation in the concept that the revenue change will always indicate profit or loss to the uility. The sample states are UP and MP which have registered losses though relation between contributions of electricity to SGDP is satisfactory.So, there are other parameters involved in registering profit or loss. If all the variable parameters favorably affect revenue pattern, then this relation between revenue growth and climate hold good. Mathematically the relation between these externalities can be expressed as follows-

$$
\mathbf{R}(\mathbf{p})=\mathbf{f}(\mathbf{u t}) *(\mathbf{p}, \mathbf{p t}) \quad \ldots \quad \ldots \quad \ldots
$$

Where, $u(t)$ is demand related attributes, $p$ is existing price and $p t$ is revised price in consistence with change in fuel price and operating cost.

\section{Revenue growth and losses}

Now ,another scenario corresponding to revenue growth and losses in the system has been analyzed .Again the gap between the supply and demand in the states is considered for the analysis to observe whether demand pattern driving the supply of electricity has any impact on the revenue realization from its consumer base, Peak demand for this purpose ,The data related to power position in the year of 2014-15 has been considered[5], The following graph represent the variation of revenue growth with losses incurred in electricity transmission and distribution. Again the analysis is focused on the states which are placed on the top rank of the profit achiever and bottom placeholder of loss incurring states in order of ranking for the year 201415.accordingly,Maharashtra,Delhi,Gujrat,WB,Karnataka,UP,Rajasthan,Tamilnadu,MP and J\&K states have been considered. System losses is inevitable according to the law of thermodynamics, because input of resources will not be transformed into full quantity of output ,but there is abnormal system losses due to technical and commercial reasons that affect the revenue growth. The study attempts to find out how the externalities and internalities affect the revenue growth of electricity utilities, here again we have focused on economical, climate and the socio economic factors. The country has been considered in four major zones where the above four factors are different from each other, the application of fuel resources are of

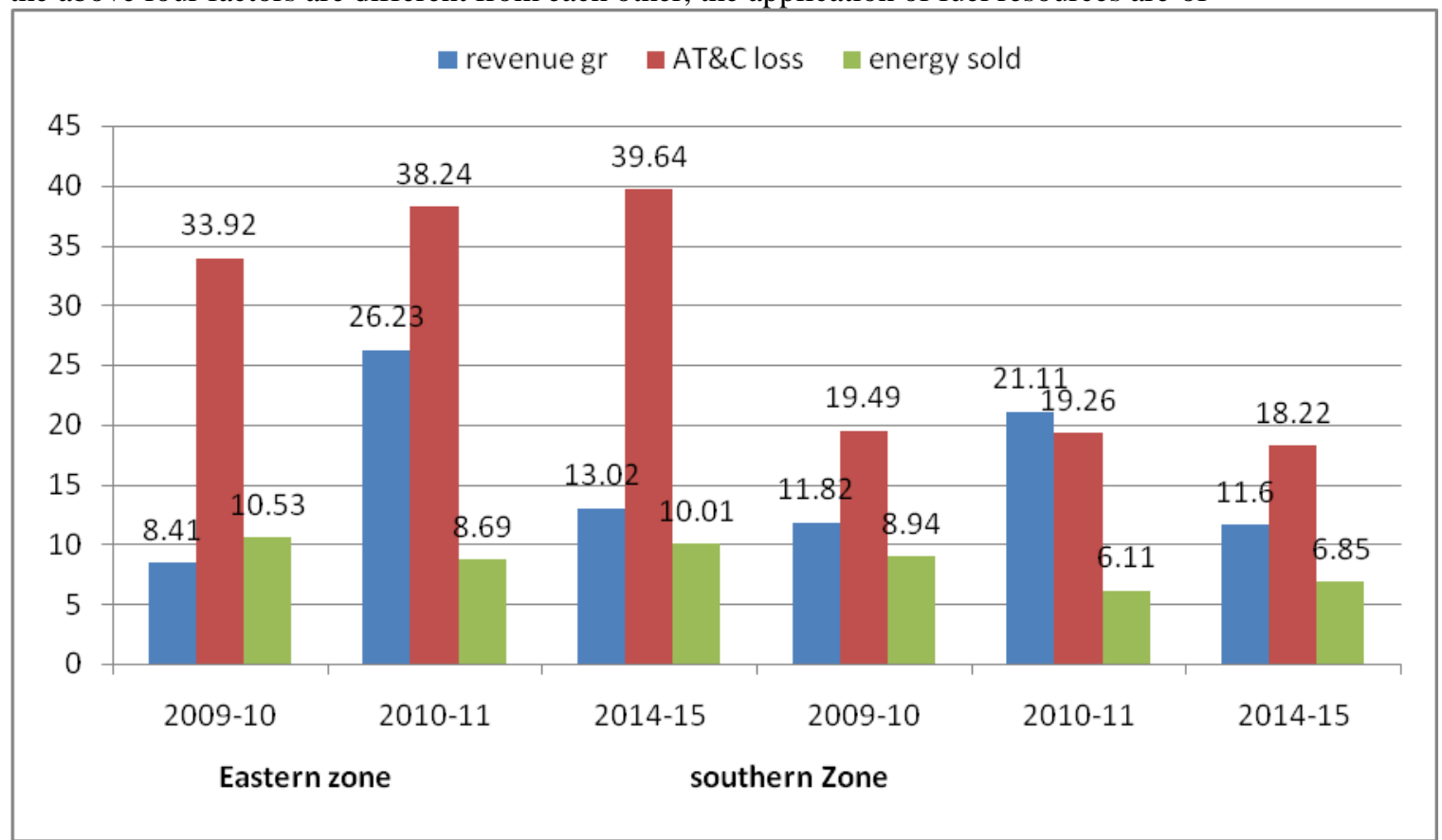

Source: data PFC annual Performance report \&lgbr report CEA

Figure 3 comparative illustrations of major dimensions

diverse type according to availability of the natural resources. The major parameters to account for these losses are energy sold (Mkwh), revenue growth and AT\&C losses which were considered for 2009-10, 2010-11 and 2013-14 that has been illustrated in figure $3 \& 4$. 


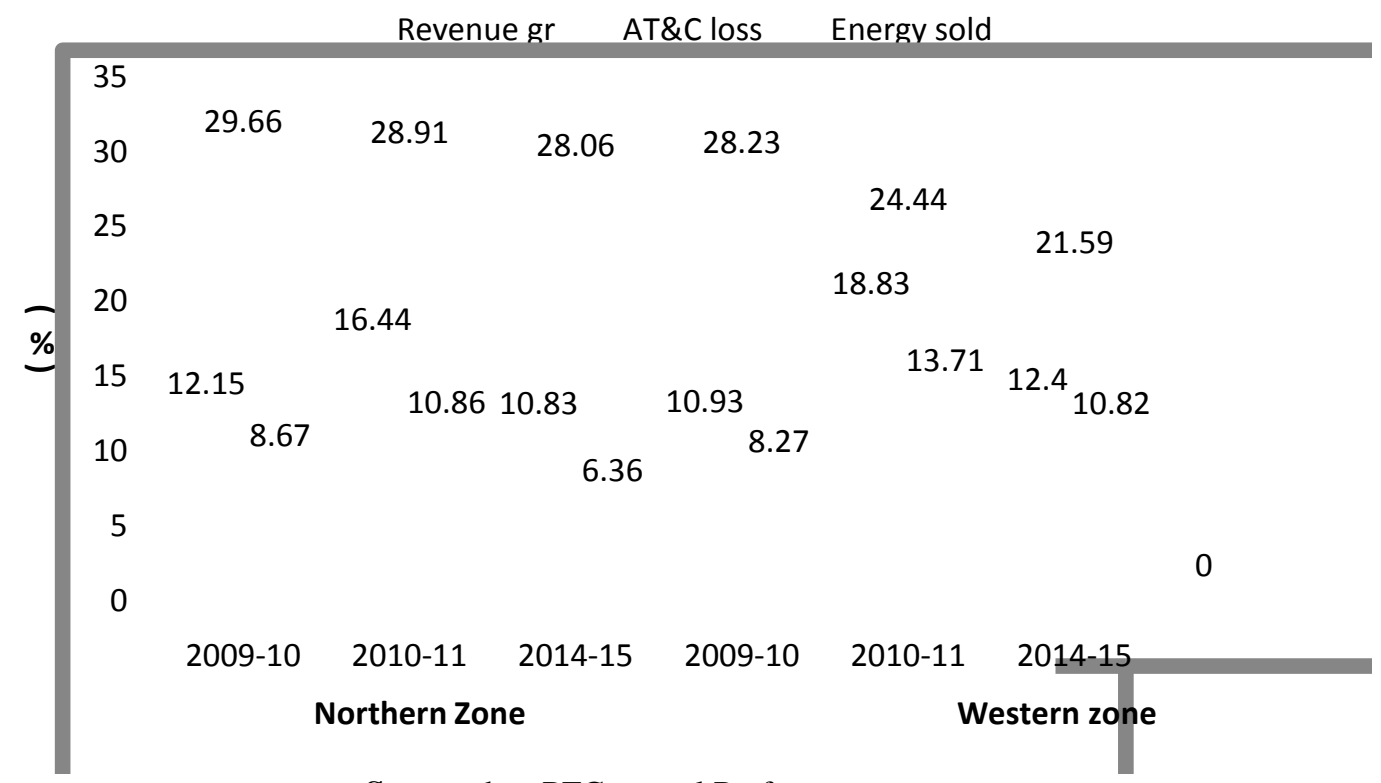

Source data PFC annual Performance report

Figure 4 comparative illustrations of major dimensions

The graphical analysis of relationship between revenue growth and variation of AT \& C losses indicate that the parameters variation is in consistence in respect of western, Northern and southern zone except in the case of eastern zone because of dominant load of service sector and tariff prevailing in the states. Industrial based load in western region, however show slump in growth corresponding to low economic growth during the years 2008-11.The resources for electricity generation is of diverse type according to availability of natural resources at different places. There is significant disproportion in relative variation of these parameters. Revenue growth is not in consistence with energy sold and AT\&C losses which is not proportionately equal. There is also issue on electricity sale price which is different in different states. However, declining trend of AT\&C losses with corresponding increase in revenue growth has been observed in western region. Mathematically these criteria can be expressed as follows

$$
\mathrm{R}(\mathrm{p})=\mathrm{f}[\mathrm{v}(\mathrm{t})](\mathrm{p}, \mathrm{pt})
$$

Where $\mathrm{v}(\mathrm{t})$ is losses incurred due to externalities impact on the system

\section{Discussion}

The analysis suggests an idea of mathematical relationships between revenue growth, state of economy, variation of climate and the losses in the system. The equation (1), (2) \& (3) may be rewritten based on the above analysis

$$
\int R(p)=f\left[e^{\wedge}(X)+u(t) *(p, p t)+v(t) *(p, p t)\right] \ldots
$$

Then the equation has been validated by substituting actual data for SGDP, AT\&C losses in

Table 3 validation of Mathematical expression

\begin{tabular}{|l|l|l|l|l|}
\hline Year & Top 5 States ;profit registered & $\begin{array}{l}\text { R(p) index } \\
\text { mean value }\end{array}$ & Bottom 5 states losses registered & $\begin{array}{l}\text { R(p) } \\
\text { mean value }\end{array}$ \\
\hline 2009-10 & $\begin{array}{l}\text { Delhi,WB,AP,Gujrat,Kerala, } \\
\text { Karnataka }\end{array}$ & $\mathbf{0 . 6 4 0}$ & Tamilnadu,UP,J\&K,MP,Bihar & $\mathbf{0 . 4 5 0}$ \\
\hline 2010-11 & Gujrat,WB,Kerala,Karnatak & $\mathbf{0 . 8 0 7}$ & $\begin{array}{l}\text { Tamilnadu,UP,MP,J\&K,Bihar,Pun } \\
\text { jab }\end{array}$ & $\mathbf{0 . 1 7 1}$ \\
\hline 2014-15 & $\begin{array}{l}\text { Maharashtra,Delhi,Gujrat,WB,Ka } \\
\text { rnatak }\end{array}$ & $\mathbf{0 . 8 4 9 4}$ & UP,Rajasthan,MP,J\&K & $\mathbf{0 . 6 7 5}$ \\
\hline
\end{tabular}

Respect of the top ranked states which were registered as profit gained and losses incurred according to the report [1].The result is tabulated in Table 3.The $\mathrm{R}(\mathrm{p})$ index is within limit

$$
0.6 \leq \text { revenue growth } \mathrm{r}(\mathrm{p}) \text { index } \leq 1
$$

This is the limitation set up for revenue growth and the selling price of electricity is determined by following steps

Step 1 compute $\mathrm{x}$

Step 2 computes $\mathrm{u}(\mathrm{t})$ 


$$
=\text { average demand/maximum demand } * \text { average rainfall/maximum rainfall }
$$

Step 3 computes $v(t)$

$=$ average loss /maximum loss

Step 3 set $\mathrm{r}(\mathrm{p})$ between 0.7 and 1.0

Determine revised selling price of electricity $\mathrm{p}(\mathrm{t})$ by substituting values in equation (4).

If the electricity selling price is fixed at this rate then revenue earned will increase profit.

The revenue growth index signifies the revenue growth is depended on SGDP, losses and demand growth. Because the $R(p)$ index result on the higher level of 0.8 is in consistence with the data in respect profit registered states.Similarly, $\mathrm{R}(\mathrm{p})$ index corresponding to lower limit of 0.607 that is in consistence with actual data of loss incurring states.

\section{Conclusion}

The study begins with the objective to justify that externalities are influencing the revenue growth criteria of the state electricity utilities, the analysis on this subject involves impact of economy, climate and losses on system demand.The analysis justified the correlation between SGDP and revenue growth, because electricity industry is contributing to SGDP. So, increase or decrease of system demand with variation of SGDP is affecting revenue growth within the constraint of loss factor and sale price of electricity in consistence with changing pattern of related variables. The study has been done on selected state utilities' performance on the basis of their rankings in top five profit registered states and bottom five loss incurred states. The three basic relation between change of revenue growth and externalities in terms of growth of SGDP,climate and losses in the system has been synthesized in a mathematical expression representing revenue growth index $R(p)$. This index value has been evaluated for those selected states on substituting real values of the parameters. This has been presented in table 3 that implies the scale of $\mathrm{R}(\mathrm{p})$ in between profit and losses. The study then focused on evaluating sale price of the electricity keeping in view reaching the target $R$ (p) index on the profit side. The method emphasizes development of historical database on average and maximum demand, average and maximum losses, the rainfall statistics and the SGDP growth. The study finally concludes that the utilities may achieve profit overcoming the constraints of externalities impact if sale price is logically fixed up. The limitation of revenue growth index has been set up; this index has justified the concept on externalities effect on economic growth. The study observed that uncontrollable external element exerting a driving force on the operation of system parameters can be neutralized by controllable parameters in internal system. The internal parameters monitor changing pattern of economy in the environment, development of revenue collection infrastructures and policy by application of advanced technology, development of knowledge and skill of human resources.

\section{References}

[1]. Performance report of State Power Utilities (2009 - 2015),Power Finance Corporation, retrieved from www.pfcindia.com/home.aspx

[2]. Data book for DCH 28 $8^{\text {th }}$ oct.2011, India Economy related and state plan related, planning commission, retrieved from www.planningcommission.nic.in

[3]. National statistics, retrieved from https://data.gov.inData .Gov.in

[4]. Rainfall information, district wise rainfall-last five years (2010-2015), (Indian Metrological Department, retrieved from www. hydro.imd.gov.in/hydrometer/,accessed on 04/01/2016

[5]. Actual Power supply Position in terms of peak demand vis-à-vis of various states system during the year 2014-15, Load Generation Balance, Central Electricity Authority, retreieved from www.cea.nic.in 